\title{
HUBUNGAN PERANAN KEPEMIMPINAN DENGAN DISIPLIN KERJA TENAGA KESEHATAN DI UPT PUSKESMAS PADANG BULAN TAHUN 2019
}

\author{
Pinta Alfiani Telaumbanua(1), Rapael Ginting ${ }^{2}$ \\ Universitas Prima Indonesia, Medan, Indonesia \\ Jln. Sekip Simp Sikambing - Medan Sumatera Utara \\ E-mail: pintaalfiani@gmail.com \\ DOI : https://doi.org/10.35451/jkg.v2i1.202
}

\begin{abstract}
Discipline is a matter that becomes a benchmark to find out whether the overall role of the leader can be carried out properly or not. Discipline must be upheld in an organization, without the support of the discipline of health workers it is difficult to realize its goals, so discipline is the key to the success of an organization in achieving its goals. This type of research uses analytic survey method with cross sectional design, to explain the relationship between the role of leadership and work discipline at UPT Puskesmas Padang Bulan. With a total of 48 respondents, the total sampling technique is to make the entire population into the study sample. The results of bivariate analysis using the Chi-Square Test obtained $p$ value $=0.004$ ( $p$ value $<0.05$ ), meaning Ha was accepted and Ho was rejected, which means there was a significant relationship between communication with the workforce health discipline at the Padang Bulan Health Center UPT 2019. The results of bivariate analysis using the Chi-Square Test obtained $p$ value $=0.001$ ( $p$ value $<0.05$ ), meaning that Ha is accepted and Ho is rejected, which means there is a significant relationship between Direction and Guidance with the discipline of health workforce at UPT Padang Bulan Health Center in 2019. It is hoped that leaders will improve communication, direction and guidance for health workers to create a condition of good work discipline.
\end{abstract}

Keywords: Leadership, Work discipline, Direction and Guidance

\section{Pendahuluan}

Pentingnya penerapan disiplin dalam suatu organisasi agar semua pegawai yang ada dalam organisasi tersebut bersedia dengan sukarela mematuhi serta mentaati setiap tata tertib yang berlaku tanpa ada paksaan. Pegawai yang disiplin dan tertib menaati semua norma-norma dan peraturan yang berlaku dalam organisasi atau instansi dapat meningkatkan kinerja pegawai. Disiplin merupakan suatu hal yang menjadi tolak ukur untuk mengetahui apakah peran pimpinan secara keseluruhan dapat dilaksanakan dengan baik atau tidak (9).

Tanpa adanya sikap disiplin dari tenaga kesehatan maka menjadi hal yang mustahil dalam pencapaian tujuan seperti yang diinginkan. Kedisiplinan harus ditegakan dalam suatu organisasi, tanpa dukungan disiplin tenaga kesehatan sulit untuk mewujudkan tujuannya. Jadi disiplin adalah kunci keberhasilan suatu organisasi dalam mencapai tujuannya (3).

Menanamkan disiplin kerja tenaga kerja dapat dikembangkan pula dengan cara kepemimpinan yang dapat dijadikan 
panutan atau teladan bagi para tenaga kerja. Didepan selalu memberikan teladan, ditengah selalu membangkitkan semangat dan dibelakang selalu bertindak sebagai motivator (17).

Disiplin Kerja memiliki cakupan antara lain yaitu Disiplin waktu diartikan sebagai sikap atau tingkah laku yang menunjukkan ketaatan terhadap jam kerja yang meliputi kehadiran dan kepatuhan pegawai pada jam kerja, pegawai melaksanakan tugas dengan tepat waktu dan benar. Disiplin peraturan diartikan sebagai peraturan maupun tata tertib yang tertulis dan tidak tertulis dibuat agar tujuan suatu organisasi dapat dicapai dengan baik, berarti taat dan patuh dalam melaksanakan perintah dari atasan dan peraturan, tata tertib yang telah ditetapkan. Serta ketaatan pegawai dalam menggunakan kelengkapan pakaian seragam yang telah ditentukan organisasi (15).

Seorang pemimpin memegang peranan yang sangat penting dalam mencapai tujuan organisasi yang telah ditetapkan. Hampir seluruh kegiatan yang ada didalam organisasi selalu memerlukan peranan seorang pemimpin di dalam mengatur tenaga kerjanya. Peranan pimpinan didalam meningkatan kedisiplinan tenaga kerja yang tinggi mencerminkan keadaan karyawan yang dapat bekerja dengan baik dan penuh konsentrasi untuk bekerja. Selanjutnya dalam upaya pimpinan memberikan suatu kepuasan kerja kepada tenaga kerjanya dalam usaha meningkatkan suatu kedisiplinan kerja yang diharapkan melalui adanya pemberian motivasi bagi karyawan (5).

Seorang pemimpin dengan kualitas kepemimpinan yang dimilkinya bukan sekedar berusaha melaksanakan tugas dan berbagai rutinitas pekerjaan saja, namun lebih dari itu pemimpin merupakan simbol dari organisasinya. Kepemimpinan merupakan satu aspek penting dalam organisasi yang merupakan faktor penggerak organisasi melalui penanganan perubahan dan manajemen yang dilakukannya, sehingga keberadaan pemimpin bukan hanya sebagai simbol yang ada atau tidaknya tetapi keberadaannya memberi dampak postif bagi perkembangan organisasinya (2).

Menurut penelitian Mahendra (2014) tentang "pengaruh kepemimpinan terhadap disiplin kerja menunjukan bahwa hubungan antara kepemimpinan dengan disiplin kerja ada-lah signifikan dengan $t$ statistik sebesar 5,192196 $(>1,96)$. Nilai original sampel estimate adalah positif yaitu sebesar 0,467362 yang menunjukkan bahwa arah hubungan antara kepemimpinan dan disiplin kerja adalah positif. Dengan demikian hipotesis 1 (H1) dalam penelitian ini yang menyatakan bahwa 'Kepemimpinan berpengaruh signifikan terhadap Disiplin Kerja di RSJ Menur Surabaya'(17).

Salah satu unit organisasi yang dibawahi oleh seorang pemimpin yaitu puskesmas. Puskesmas merupakan unit pelaksanaan teknis dinas kesehatan kabupaten atau kota yang bertanggung jawab menyelenggarakan pembangunan kesehatan di suatu wilayah kerja. Berdasarkan Peraturan Menteri Kesehatan Nomor 75 Tahun 2014 tentang Pusat Kesehatan Masyarakat, Puskesmas adalah fasilitas kesehatan yang menyelenggarakan upaya kesehatan masyarakat dan upaya kesehatan perseorangan tingkat pertama, dengan lebih mengutamakan upaya promotif dan preventif, untuk mencapai derajat kesehatan masyarakat yang setinggitingginya di wilayah kerjanya. Untuk mendukung fungsi dan tujuan Puskesmas diperlukan sumber daya manusia kesehatan baik tenaga kesehatan maupun tenaga penunjang kesehatan(7).

Kepemimpinan akan berlangsung efektif bilamana mampu memenuhi fungsinya untuk memandu, menuntun, membimbing, memberi atau membangun motivasi-motivasi kerja, mengemudikan 
organisasi, menjalin jaringan-jaringan komunikasi yang baik, memberikan pengawasan yang efisien, dan membawa para pengikutnya kepada sasaran yang ingin dicapai (8).

Oleh sebab itu kepemimpinan harus memiliki kemampuan untuk mengarahkan, membimbing pegawainya, adanya komunikasi antar dua belah pihak, sehingga timbulnya kepercayaan pegawai terhadap suatu instansi dimana pegawai merasa suatu instansi dapat memenuhi apa yang menjadi kebutuhannya dan instansi memberikan perlakuan yang adil terhadap pegawai dan hal ini akan meningkatkan displin kerja tenaga kesehatan (6).

Kepala Puskesmas sebagai pemimpin yang baik harus memiliki kemampuan berkomunikasi dengan bawahan/stafnya agar mampu bekerja sama dengan baik, selalu memberikan arahan dan bimbingan sebelum melaksanakan suatu program kegiatan, memantau pegawai pada saat bekerja, mampu mendorong semangat kerja pegawai. Kemampuan pemimpin dalam mengarahkan serta mengkoordinasikan potensi yang dimiliki oleh pegawai akan mempengaruhi peningkatan disiplin kerja para bawahannya (19).

Kepala puskesmas selaku pemimpin mampu melaksanakan peran komunikasinya dengan cara menyatukan seluruh aspek untuk mencapai kepentingan bersama maka terjadi pula tujuan atau target puskesmas.

Seorang pemimpin harus mampu memberikan arahan dan bimbingan kepada bawahannya, dalam konteks puskesmas unuk mencapai keberhasilan program maka bawahan mau mendengar dan mengerti serta mau dibimbing oleh pemimpin. Pemimpin tentunya harus mampu memberikan arahan dan membimbing bawahan supaya disiplin dalam menjalankan tugasnya.

Dalam suatu organisasi fungsi pengawasan sangat dibutuhkan, dengan pengawasan yang baik dapat mencegah timbulnya penyimpangan dan menjamin bahwa pelaksanaan kegiatan organisasi berjalan sesuai dengan rencana yang ditentukan.

Peranan kepemimpinan dalam memotivasi bawahannya sangat mempengaruhi disiplin kerja tenaga kesehatan. Pemimpin harus mampu memberikan inspirasi, semangat dan dorongan dalam melakukan tugas supaya para pegawai tidak malas dan lebih disiplin dalam waktu kerja.

Berdasarkan survei awal yang dilakukan pada bulan Juli 2018, ditemukan permasalahan yaitu tingkat disiplin tenaga kesehatan masih belum baik. Hal ini terlihat dari tingkat kehadiran tenaga kesehatan sebesar $50 \%$ dan tidak memberikan keterangan jika tidak hadir $40 \%$ tidak sesuai dengan jam kerja yang telah di tetapkan. Adapun jam kerja tenaga kesehatan yaitu seninsabtu (Pukul 08.00-16.00 WIB). Namun masih ada pegawai yang tidak mematuhi ketentuan jam kerja tersebut, datang ke puskesmas lewat dari jam masuk yang telah ditetapkan dan pulang dari puskesmas sebelum waktunya.

Kemudian masih ada beberapa pegawai yang tidak mematuhi ketaatan seperti tidak memakai pakaian seragam dan masih pakai sandal ketika berada di puskesmas $50 \%$ dan tenaga kesehatan dalam melaksanakan tanggung jawabnya masih kurang baik sebesar $50 \%$, seperti yang telah diamati ada beberapa tenaga kesehatan yang sering berkumpulkumpul meskipun masih waktu jam kerja dan seperti yang diketahui bahwa kepala puskesmas tidak tinggal atau menetap di puskesmas.

Disiplin dalam bekerja $30 \%$ hal ini disebabkan kurangnya arahan dan bimbingan dari kepala puskesmas yang dapat mendorong tenaga kesehatan dalam menjalankan tugas dan tidak ada sanksi yang diberikan oleh kepala puskesmas terhadap tenaga kesehatan yang tidak disiplin dalam melaksanakan tugas dan tanggungjawabnya. 
Dari wawancara yang dilakukan peneliti kepada beberapa tenaga kesehatan bahwa tingkat kehadiran kepala puskesmas di tempat kerja masih $60 \%$, tidak setiap hari berada di puskesmas karena ada urusan pribadi dan adanya rapat diluar puskesmas sehingga tenaga kesehatan kurang mendapat bimbingan dan arahan terhadap kinerja mereka sehingga tenaga kesehatan mengabaikan peraturan yang telah ditetapkan.tidak terjalinnya komunikasi yang baik antara pemimpin dan tenaga kesehatan sehingga mengakibatkan disiplin kerja tenaga kesehatan menurun. Tujuan penelitian ini adalah untuk mengetahui Hubungan Peranan Kepemimpinan Dengan Disiplin Kerja Tenaga Kesehatan Di UPT Puskesmas Padang Bulan Tahun 2019.

\section{METOde PENELITIAN}

Penelitian ini merupakan jenis penelitian yang menggunakan metode survei analitik yang bertujuan mengetahui Hubungan peranan kepemimpinan dengan Disiplin Kerja Di UPT puskesmas Padang bulan. Rancangan Penelitian yang digunakan dalam penelitian ini adalah ini adalah cross sectiona $(10,11)$.

Populasi dalam penelitian ini adalah seluruh tenaga kesehatan yang bekerja di UPT Puskesmas Padang Bulan Tahun 2018 sebanyak 48 orang. Teknik pengambilan sampel dalam penelitian ini menggunakan teknik total sampling yaitu menjadikan seluruh populasi masuk kedalam sampel penelitian, yaitu seluruh tenaga kesehatan yang bekerja di UPT Puskesmas Padang Bulan Tahun 2018 sebanyak 48 orang(11-13).

Penelitian ini dilakukan pada bulan Juni 2019. Pengumpulan data dalam penelitian dilakukan dengan wawancara dengan menggunakan alat bantu kuesioner. Uji Satistik pada analisis data menggunakan Uji Chi Square $\left(\mathrm{X}^{2}\right)$ dengan tingkat kepercayaan 95\% menggunakan program SPSS versi 16.0 .

\section{HASIL PENELITIAN}

\section{Distibusi Frekuensi Karakteristik Responden}

Berdasarkan tabel 1 diperoleh disitribusi frekuensi jenis kelamin, mayoritas responden berjenis kelamin perempuan sebanyak 41orang $(85,4 \%)$ dan minoritas berjenis kelamin laki - laki sebanyak 7 orang $(14,6 \%)$. distribusi Frekuensi kelompok umur dari 48 responden, mayoritas responden kelompok umur $32-41$ tahun sebanyak 21 orang $(43,8 \%)$ dan minoritas kelompok umur 52 -60 tahun sebanyak 10 orang $(20,8 \%)$. distribusi pendidikan responden mayoritas pendidikan S1 sebanyak 21 orang $(43,8 \%)$ dan minoritas pendidikan DIII sebanyak 13 orang $(27,1 \%)$.

Tabel 1

Karakteristik Responden

\begin{tabular}{ccc}
\hline $\begin{array}{c}\text { Jenis } \\
\text { Kelamin }\end{array}$ & $\begin{array}{c}\text { Frekue } \\
\text { nsi (n) }\end{array}$ & $\begin{array}{c}\text { Present } \\
\text { ase (\%) }\end{array}$ \\
\hline $\begin{array}{c}\text { Laki-Laki } \\
\text { Perempu } \\
\text { an }\end{array}$ & 41 & 14,6 \\
85,4 \\
\hline Umur & & \\
\hline $32-41$ & 21 & 43,8 \\
$42-51$ & 17 & 35,4 \\
$52-60$ & 20 & 20,8 \\
\hline Pendidi & & \\
kan & & \\
\hline SMA & 14 & 29,2 \\
Akademi & 13 & 27,1 \\
Sarjana & 21 & 43,8
\end{tabular}

\section{Distribusi Frekuensi Variabel Bebas Penelitian}

Berdasarkan tabel 2 dapat dilihat bahwa Komunikasi, mayoritas responden menilai peranan kepemimpinan adalah tidak baik sebanyak 30 orang $(62,5 \%)$ dan minoritas responden menilai peranan kepemimpinan baik sebanyak 18 orang $(37,5 \%)$.

Berdasarkan Arahan dan Bimbingan, mayoritas responden menilai peranan kepemimpinan adalah tidak baik 
sebanyak 26 orang $(54,2 \%)$ dan minoritas responden menilai peranan kepemimpinan sebanyak 22 orang $(45,8 \%)$.

Berdasarkan Pengawasan, mayoritas responden menilai peranan kepemimpinan adalah tidak baik sebanyak 28 orang $(58,3 \%)$ dan minoritas responden menilai peranan kepemimpinan baik sebanyak 20 orang $(41,7 \%)$.

Berdasarkan Motivasi, mayoritas responden menilai peranan kepemimpinan tidak baik sebanyak 31 orang $(64,6 \%)$ dan minoritas responden menilai peranan kepemimpinan baik sebanyak 17 orang $(35,4 \%)$.

Tabel 2

\begin{tabular}{lcc}
\multicolumn{1}{c}{ Distribusi Variabel Bebas Penelitian } \\
\hline \multicolumn{1}{c}{ Variabel } & $\begin{array}{c}\text { Frekuen } \\
\text { si (n) }\end{array}$ & $\begin{array}{c}\text { Persentas } \\
\text { e (\%) }\end{array}$ \\
\hline $\begin{array}{l}\text { Komunikasi } \\
\text { Baik }\end{array}$ & 18 & 37,5 \\
Tidak Baik & 30 & 62,5 \\
\hline $\begin{array}{l}\text { Arahan dan } \\
\text { Bimbingan } \\
\text { Baik }\end{array}$ & 22 & 45,8 \\
Tidak Baik & 26 & 54,2 \\
\hline $\begin{array}{l}\text { Pengawasa } \\
\text { n }\end{array}$ & & \\
$\begin{array}{l}\text { Baik } \\
\text { Tidak Baik }\end{array}$ & 20 & 41,7 \\
\hline $\begin{array}{l}\text { Motivasi } \\
\text { Baik }\end{array}$ & 28 & 58,3 \\
Tidak Baik & 17 & 35,4 \\
\hline
\end{tabular}

\section{Analisis Bivariat}

Berdasarkan tabel 3 di bawah diperoleh Hasil analisi bivariat dengan menggunakan Uji Chi-Square diperoleh nilai $p$ value $=0,004(p$ value $<0,05)$, artinya $\mathrm{Ha}$ diterima dan $\mathrm{Ho}$ ditolak, yang artinya ada hubungan yang signifikan antara komunikasi dengan disiplin kerja tenaga kesehatan di UPT Puskesmas Padang Bulan Tahun 2019.

Hasil analisi bivariat dengan menggunakan Uji Chi-Square diperoleh nilai $p$ value $=0,001$ ( $p$ value $<0,05)$, artinya Ha diterima dan Ho ditolak, yang artinya ada hubungan yang signifikan antara Arahan dan Bimbingan dengan disiplin kerja tenaga kesehatan di UPT Puskesmas Padang Bulan Tahun 2019.

Hasil analisi bivariat dengan menggunakan Uji Chi-Square diperoleh nilai $p$ value $=0,493$ ( $p$ value $<0,05)$, artinya Ha ditolak dan Ho diterima, yang artinya tidak ada hubungan yang signifikan antara pengawasan dengan disiplin kerja tenaga kesehatan di UPT Puskesmas Padang Bulan Tahun 2019.

Hasil analisi bivariat dengan menggunakan Uji Chi-Square diperoleh nilai $p$ value $=0,278$ ( $p$ value $<0,05)$, artinya Ha ditolak dan Ho diterima, yang artinya ada hubungan yang signifikan antara Arahan dan Bimbingan dengan disiplin kerja tenaga kesehatan di UPT Puskesmas Padang Bulan Tahun 2019.

Tabel 3

Pengaruh Variabel Bebas dengan Peranan Kepemimpinan

\begin{tabular}{|c|c|c|c|c|c|c|}
\hline \multirow{3}{*}{ Variabel } & \multicolumn{4}{|c|}{$\begin{array}{c}\text { Peranan } \\
\text { Kepemimpinan }\end{array}$} & \multirow{3}{*}{$\mathbf{n}$} & \multirow{3}{*}{$\%$} \\
\hline & \multicolumn{2}{|c|}{ Puas } & \multicolumn{2}{|c|}{$\begin{array}{l}\text { Tidak } \\
\text { Puas }\end{array}$} & & \\
\hline & $\mathbf{N}$ & $\%$ & $\mathbf{n}$ & $\%$ & & \\
\hline \multicolumn{7}{|l|}{ Komunikasi } \\
\hline Baik & 13 & 72,2 & 5 & 27,8 & 18 & 100 \\
\hline Tidak Baik & 9 & 30,0 & 21 & 70,0 & 30 & 100 \\
\hline \multicolumn{7}{|l|}{$\begin{array}{l}\text { Arahandan } \\
\text { Bimbingan }\end{array}$} \\
\hline Baik & 16 & 72,7 & 6 & 27,3 & 22 & 100 \\
\hline Tidak Baik & 6 & 23,1 & 20 & 76,9 & 26 & 100 \\
\hline
\end{tabular}

\section{Pengawasan}

Baik

$840,012 \quad 60,020100$ ।

Tidak Baik

$1450,014 \quad 50,0 \quad 28100$

\section{Motivasi}

Baik

$\begin{array}{llllll}6 & 35,3 & 11 & 64,7 & 17 & 100\end{array}$

Tidak Baik

$16 \quad 51,6 \quad 15 \quad 48,431 \quad 100$ 
Pemimpin memberikan masukan dan penjelasan terhadap pekerjaan namun tenaga kesehatan tidak menerima

\section{PEMBAHASAN}

\section{Pengaruh Komuniasi sebagai Peranan Kepemimpinan dengan Disiplin Kerja Tenaga Kesehatan di UPT Puskesmas Padang Bulan Tahun 2019}

Berdasarkan hasil penelitian dengan menggunakan uji Chi-Square Test dapat diketahui dari hasil uji statistik diperoleh nilai $\mathrm{p}$ value $=0,004$, maka dapat disimpulkan bahwa ada pengaruh antara Komuniasi sebagai Peranan Kepemimpinan dengan Disiplin Kerja Tenaga Kesehatan di UPT Puskesmas Padang Bulan Tahun 2019.

Hal ini sejalan dengan penelitian dila dan Rochmah (2015), tentang Anlisis pengaruh komunikasi, kepemimpinan dan tim kerja terhadap kedisiplinan pegawai Rumah sakit Surabaya, dari 58 responden diketahui bahwa mayoritas responden menilai efektivitas komunikasi rumah sakit terkait penegakan kedisiplinan dalam kategori kurang efektif. Hal ini menunjukan bahwa masih terdapat fungsi komunikasi yang belum berjalan dengan optimal dalam menegakan kedisiplinan bagi pegawai rumah sakit antara fungsi motivasi dari pimpinan dan penyampaian informasi. Hasil dari uji regresi linier menunjukan bahwa $=0,024$ sehingga dapat disimpulkan bahwa terdapat pengaruh antara tingkat komunikasi dengan kedisiplinan pegawai(1).

Menurut asumsi peneliti, hasil penelitian ini sesuai dengan teori (Luthans, 2012) yaitu komunikasi yang tidak efektif dikatakan sebagai akar semua permasalahan. Berdasarkan hasil penelitian yang telah dilakukan bahwa komunikasi dari pemimpin sudah baik namun disiplin kerja masih tidak baik disebabkan oleh perbedaan pendapat antara tenaga kesehatan dengan pemimpin. masukan dari pemimpin. sehingga terjadi kesenjangan komunikasi antar tenaga kesehatan dengan pemimpin(8).

Peranan kepemimpinan dalam hal komunikasi berhubungan dengan disiplin kerja tenaga kesehatan, apabila komunikasi pemimpin baik kepada tenaga kesehatan akan meningkatkan disiplin kerja namum sebaliknya jika komunikasi antar pemimpin dan tenaga kesehatan tidak baik akan maka disiplin kerja pun tidak baik.

\section{Pengaruh arahan dan bimbingan sebagai Peranan Kepemimpinan dengan Disiplin Kerja Tenaga Kesehatan di UPT Puskesmas Padang Bulan Tahun 2019}

Hasil analisi bivariat dengan menggunakan Uji Chi-Square diperoleh nilai $p$ value $=0,001$ ( $p$ value $<0,05)$, artinya Ha diterima dan Ho ditolak, yang artinya ada hubungan yang signifikan antara Arahan dan Bimbingan dengan disiplin kerja tenaga kesehatan di UPT Puskesmas Padang Bulan Tahun 2019.

Hal ini sejalan dengan hasil penelitian Rafidah (2017), tentang hubungan peranan kepemimpinan dengan disiplin kerja pegawai di UPT Puskesmas Indrapura Kecamatan Air Putih, diperoleh hasil pengujian statistik untuk hubungan arahan dan bimbingan dengan disiplin kerja ternyata terdapat hubungan signifikan dengan disiplin kerja pegawai puskesmas indrapura yang ditunjukan pada nilai $p$ value $=0,006<$ 0,05 artinya, dapat disimpulkan terdapat hubungan signifikan antara kedua variabel(14).

Menurut asumsi peneliti, penelitian ini sesuai dengan teori (Hasibuan, 2011) yaitu arahan dan bimbingan adalah perihal kepala puskesmas mengatur dan mengarahkan pelaksanaan pada organisasi untuk menghasilkan suatu 
tindakan yang baik pada pegawai puskesmas sehingga peraturan dengan tindakan yang dilaksanakan tidak saling bertentangan atau simpangsiur(4).

Berdasarkan hasil penelitian bahwa pemimpin jarang memberikan arahan dan bimbingan kepada tenaga kesehatan dikarenakan pemimpin tidak slalu datang ke puskesmas karena urusan dinas, sehingga tenaga kesehatan tidak disiplin dan merasa kesulitan dalam melakukan pekerjaannya serta pemimpin tidak pernah memberikan tanggapan atas hasil kerja yang dilakukan oleh tenaga kesehatan. Hal ini yang menyebabkan disiplin kerja tenaga kesehatan menjadi tidak baik.

\section{Pengaruh pengawasan sebagai Peranan Kepemimpinan dengan Disiplin Kerja Tenaga Kesehatan di UPT Puskesmas Padang Bulan Tahun 2019}

Hasil analisi bivariat dengan menggunakan Uji Chi-Square diperoleh nilai $p$ value $=0,493$ ( $p$ value $<0,05)$, artinya Ha ditolak dan Ho diterima, yang artinya tidak ada hubungan yang signifikan antara pengawasan dengan disiplin kerja tenaga kesehatan di UPT Puskesmas Padang Bulan Tahun 2019.

Hal ini tidak sejalan dengan hasil penelitian putra (2016), tentang beberapa faktor yang mempengaruhi disiplin kerja pegawai negri sipil puskesmas se Kabupaten Dompu, diperoleh hasil uji Hipotesis hubungan pengawasan dengan disiplin kerja dengan nilai $P$ value $=0,05$. Dengan demikian dapat disimpulkan bahwa pengawasan berpengaruh secara positif terhadap disiplin kerja pegawai negri sipil Puskesmas se Kabupaten Dompu. Kedua variabel ini memiliki hubungan artinya pengawasana mempengaruhi tingkat disiplin kerja pegawai. Semakin efektif pengawasan yang dilakukan oleh pemimpin maka semakin baik disiplin kerja pegawai(13).
Menurut asumsi peneliti, hal ini sesuai dengan teori (Siagian, 2015) yaitu pengawasan adalah keseluruhan upaya pengamatan pelaksanaan kegiatan operasional guna menjamin bahwa berbagai kegiatan tersebut sesuai dengan rencana yang telah ditetapkan sebelumnya(18).

Pengawasan merupakan alat yang ampuh untuk meningkatkan produktivitas kerja seperti halnya untuk meningkatkan disiplin kerja. Jika pengawasann pemimpin baik maka disiplin kerja akan baik begitu sebaliknya jika pengawasan dari pemimpin tidak baik maka tingkat disiplin pun tidak baik. Dalam suatu organisasi peranan pemimpin dalam penagwasan sangatlah dibutuhkan, dengan pengawasan yang baik dapat mencegah timbulnya masalah dalam pelaksanaan kegiatan dan kegiatan organisasi berjalan sesuai dengan rencana yang telah dibutuhkan, pengawasan juga merupakan kewajiban pemimpin terhadap bawahannya, dengan adanya pengawasan pemimpin dapat mengetahui kegiatan nyata dari setiap aspek dan setiap permasalahan pelaksanaan tugas dalam lingkungan puskesmas. Berdasarkan hasil penelitian bahwa pemimpin selalu melakukan pengawasan, mengoreksi hasil pekerjaan tenaga kesehatan serta sering meninjau ruangan kerja pada saat jam kerja, sehingga tenaga kesehatan disiplin dalam bekerja.

\section{Pengaruh Motivasi sebagai Peranan Kepemimpinan dengan Disiplin Kerja Tenaga Kesehatan di UPT Puskesmas Padang Bulan Tahun 2019}

Hasil analisi bivariat dengan menggunakan Uji Chi-Square diperoleh nilai $p$ value $=0,278 \quad(p$ value $<0,05)$, artinya Ha ditolak dan Ho diterima, yang artinya ada hubungan yang signifikan antara Motivasi dengan disiplin kerja tenaga kesehatan di UPT Puskesmas Padang Bulan Tahun 2019. 
Hal ini tidak sejalan dengan hasil penelitian Said, dkk (2016), bahwa hasil uji chi square menunjukan motivasi memiliki hubungan dengan kedisiplinan petugas kesehatan di puskesmas Motaha kabupaten Konawe selatan tahun 2016. Ada hubungan antara motivasi dengan kedisiplinan Petugas kesehatan, dengan hasil uji keeratan sebesar 0,382(16).

Menurut asumsi peneliti hal ini sesuai dengan teori Patricia (2014), yaitu motivasi pada dasarnya adalah proses yang menentukan seberapa banyak usaha yang akan dicurahkan untuk melaksanakan pekerjaan. pemimpin selalu memberikan Motivasi, pelatihan pelatihan kepada tenaga kesehatan serta memberikan dukungan dan perhatian dalam menyelesaikan pekerjaan untuk meningkatkan kemampuan dan ketrampilan tenaga kesehatan(12).

Berdasarkan hasil kuesioner yang dilakukan peneliti terhadap tenaga kesehatan yang menilai aspek motivasi sebagai peranan kepemimpinan sudah cukup baik dikarenakan pemimpin masih mau memberikan penghargaan kepada pegawai yang memiliki disiplin kerja yang baik, tetapi pemimpin juga masih belum menerapkan hukuman atau sanksi kepada tenaga kesehatan yang tidak disiplin dalam bekerja padahal menerapkan hukuman bagi tenaga kesehatan yang tidak disiplin dalam bekerja merupakan salah satu peningkatan motivasi dan disiplin kerja agar pegawai terpacu untuk disiplin ditempat kerja.

\section{KESIMPULAN}

Faktor yang mempengaruhi Disiplin Kerja Tenaga Kesehatan di UPT Puskesmas Padang Bulan adalah Komuniasi sebagai Peranan Kepemimpinan, Arahan dan Bimbingan sedangkan pengawasan, dan motivasi tidak berpengaruh terhadap Disiplin Kerja Tenaga Kesehatan di UPT Puskesmas Padang.

\section{DAFTAR PUSTAKA}

1. Dila, Rohma. Analisis Pengaruh Komunikasi, Kepemimpinan dan Tim Kerja terhadap Kedisiplinan Pegawai Rumah sakit X, Surabaya. 2015;

2. Fahmi. Perilaku organiasai. Bandung: Alfabeta; 2016.

3. Hasibuan, Melayu. Manajemen Sumber Daya Manusia. Jakarta: Bumi Aksara; 2013 hal.

4. Hasibuan MSP. Manajemen Sumber Daya Manusia. Bandung: Bumi Aksara; 2011.

5. Hermanto R. Peran Pemimpin Dalam Meningkatkan Disiplin Kerja Karyawan Pada PT. Rama Bakti Estate. Pekan Baru Riau; 2010.

6. Kartono K. Pemimpin dan Kepemimpinan. Jakarta: PT. Raga Grafindo Persada; 2010.

7. Kemenkes R I. Peraturan Menteri Kesehatan Republik Indonesia Nomor 75 Tahun 2014 Tentang Pusat Kesehatan Masyarakat. In Jakarta; 2014.

8. Luthans F. Organizational Behaviour 10th Edition. United Kingdom: The McGrawHillCompanies; 2012.

9. Mahendra IG., Brahmasari I. Pengaruh Kepemimpinan terhadap Disiplin Kerja, Motivasi Kerja dan Kinerja Perawat Pelaksana di Ruang Rawat Inap RSJ Menur Surabaya. Fakultas Ekonomi Untag Surabaya. JMJ 17 J IImu Ekon Manaj. 2014;1:2242.

10. Notoatmodjo S. Metodologi Penelitian Kesehatan. Jakarta: Rineka Cipta; 2016.

11. Notoatmodjo S. Metodologi Penelitian Kesehatan. Jakarta: Rineka Cipta; 2012.

12. Petricia. Alpha Teach Yourself Management Skills. jakarta: prenada; 2014.

13. Putra SP, Asmony T, Nasir M. BEBERAPA FAKTOR YANG MEMPENGARUHI DISIPLIN KERJA PEGAWAI NEGERI SIPIL PUSKESMAS SE KABUPATEN 
DOMPU. 2016;1(8):297-306.

14. Rafidah. hubungan peranan kepemimpinan dengan disiplin kerja pegawai di UPT Puskesmas Indrapura Kecamatan Air Putih. 2017.

15. Robbins S., Coulter M. Manajemen. Jakarta: PT Indeks Kelompok Gramedia; 2005.

16. Said D. Hubungan Kepemimpina, Pengawasan dan Motivasi dengan Peningkatan Disiplin Pegawai Puskesmas Motaha, Kabupaten Konawe selatan. 2016;

17. Sastrohadiwiryo S. Manajemen Tenaga Kerja Indonesia. Jakarta: PT Bumi Aksara; 2003.

18. Siagian PS. Manajemen Sumber Daya Manusia. Jakarta: PT Bumi Aksara; 2015.

19. Siagian PS. Teori dan Praktek Kepemimpinan. Jakarta: PT Rineka Cipta; 2003.

20. Sugiyono. Metode Penelitian Pendidikan. Bandung: Alfabeta, CV; 2017.

21. Sugiyono. Metode Penelitian Kuantitatif, Kualitatif dan R\&D. Jakarta: Penerbit Alfabeta; 2017. 